\title{
EFICIÊNCIA DE EXTRATO TÂNICO COMBINADO OU NÃO COM ÁCIDO BÓRICO NA PROTEÇÃO DA MADEIRA DE Ceiba pentandra CONTRA CUPIM XILÓFAGO
}

\author{
Leandro Calegari ${ }^{1}$, Pedro Jorge Goes Lopes ${ }^{2}$, Gregório Mateus Santana ${ }^{3}$, Diego Martins Stangerlin ${ }^{4}$, \\ Elisabeth de Oliveira ${ }^{5}$, Darci Alberto Gatto ${ }^{6}$ \\ ${ }^{1}$ Eng. Florestal, Dr., CSTR, UFCG, Patos, PB, Brasil - calegari@ cstr.ufcg.edu.br \\ ${ }^{2}$ Acadêmico de Eng. Florestal, CSTR, UFCG, Patos, PB, Brasil - pj.tm@ hotmail.com \\ ${ }^{3}$ Eng. Florestal, Mestrando em Ciência e Tecnologia da Madeira, UFLA, Lavras, MG, Brasil - gregorioengflorestal@ hotmail.com \\ ${ }^{4}$ Eng. Florestal, Dr., ICAA, UFMT, Sinop, MT, Brasil - stangerlin@ufmt.br \\ ${ }^{5}$ Eng $^{\mathrm{a}}$. Florestal, Dr ${ }^{\mathrm{a}}$., CSTR, UFCG, Patos, PB, Brasil - betholiveira12@gmail.com \\ ${ }^{6}$ Eng. Florestal, Dr., Centro das Engenharias, UFPel, Pelotas, RS, Brasil - darcigatto@ yahoo.com
}

Recebido para publicação: 04/09/2012 - Aceito para publicação: 08/11/2013

\begin{abstract}
Resumo
Dentre os métodos que vêm sendo testados para minimizar a lixiviação de compostos de boro na madeira, destaca-se sua combinação com taninos vegetais. Aos taninos vegetais é atribuída a durabilidade natural da madeira de algumas espécies, indicando sua potencialidade como preservativo natural. Neste estudo, avaliou-se o rendimento de taninos condensados provenientes da casca de Mimosa tenuiflora em extração realizada com água destilada, comparando-o ao da extração envolvendo a inclusão de sulfito de sódio, assim como a eficiência de extratos tânicos sulfitados, combinados ou não com ácido bórico, na melhoria da resistência da madeira de Ceiba pentandra ao térmita xilófago Nasutitermes corniger, por meio de ensaio de preferência alimentar. Extrato tânico obtido com a inclusão de sulfito de sódio à água teve melhor rendimento em taninos condensados. De maneira geral, a impregnação da madeira com o extrato tânico sulfitado proporcionou o mesmo comportamento quando comparada à aplicação do ácido bórico, sendo os melhores resultados verificados quando ambos foram utilizados conjuntamente. No entanto, depois de aplicado na madeira, o extrato tânico foi lixiviado e não favoreceu a redução da lixiviação do ácido bórico. Apesar da potencialidade do uso do extrato tânico ao cupim xilófago, estudos adicionais fazem-se necessários.
\end{abstract}

Palavras-chave: Biodeterioração da madeira; térmitas xilófagos; Nasutitermes corniger.

\begin{abstract}
Tannic extract efficiency combined or not with boric acid on protection of Ceiba pentandra wood against xylophagous termite. Among the methods tested to reduce the leaching of boron compounds in wood, it can be highlighted their combination with vegetable tannins. It is attributed the natural durability of some species of wood to vegetable tannins, pointing to their potentiality as natural wood preservatives. This research evaluated the efficiency of condensed tannins from bark of Mimosa tenuiflora extract with distilled water, compared to another extract added of sodium sulfite. It also evaluated the efficiency of sulfited tannin extracts, combined or not with boric acid in order to improve the resistance of Ceiba pentandra against the xylophagous termite Nasutitermes corniger by feeding test. Tannic extract obtained by adding sodium sulfite to distilled water revealed better yield compared to condensed tannin extraction. In general, impregnation of wood with tannin extract presented the same behavior as compared to application of boric acid, with best results observed when both them were simultaneously used. However, after applied to wood, tannin extracted was leachable and it did not favor the boric acid leaching. Despite the potential use of tannic extract against the xylophagous termite, additional studies are required for a best evaluation.

Keywords: Wood biodeterioration; xilophogous termites; Nasutitermes corniger.
\end{abstract}

\section{INTRODUÇÃO}

Obtidos de diversas espécies florestais, porém pouco conhecidos na maioria delas por causa da sua composição variável, os taninos vegetais têm uma série de aplicações. Historicamente, sua principal aplicação é para o curtimento de peles, tornando-as imputrescíveis, transformando-as em couro. Os 
taninos ainda são empregados pela indústria cosmética, de medicamentos, de perfuração de poços, de fabricação de azulejos, de tratamento de água e esgoto e para a fabricação de tintas e adesivos. Além disso, possuem propriedades de repelência a organismos xilófagos, podendo ser responsáveis pela durabilidade natural da madeira de algumas espécies florestais, o que indica o seu potencial para ser utilizado como preservativo natural (JORGE et al., 2001; SEN et al., 2009; LIMA, 2011).

Apesar de alguns estudos justificarem a alta durabilidade natural de algumas madeiras por causa de taninos presente nas mesmas (JORGE et al., 2001; MELO et al., 2010), outros citam que os taninos possuem baixa toxicidade como preservativos, mas que podem fixar biocidas pelas suas excelentes propriedades quelantes, o que significa que possuem habilidade em formar complexos com metais (LAKS; MCKAIG, 1988; THEVENON et al., 1998; BRAND et al., 2006), dificultando sua posterior lixiviação.

Boratos como o ácido bórico, bórax e octaborato dissódico tetrahidratado são comprovadamente eficientes na proteção de madeiras, sendo tóxicos para insetos e fungos e de baixa toxicidade a mamíferos. Outra característica é sua alta solubilidade em água, permitindo que a sua introdução na madeira seja realizada por métodos como imersão (difusão) e vácuo-pressão. Porém sua alta solubilidade em água torna-os impróprios para uso em ambiente externo, por serem facilmente lixiviados (XAVIER, 2004).

Métodos diversificados vêm sendo testados para diminuir a lixiviação de compostos de boro da madeira quando em ambientes externos e/ou em contato com o solo, incluindo a preparação dos complexos de boro com taninos (PIZZI; BAECKER, 1996; COLLI et al., 2007; OBANDA et al., 2008; THEVENON et al., 2009; 2010).

A biodeterioração da madeira é causada por organismos xilófagos compreendidos basicamente por fungos, insetos, moluscos, crustáceos e bactérias, sendo os dois primeiros grupos os mais importantes, por serem responsáveis pelas maiores deteriorações (MENDES; ALVES, 1988).

No semiárido brasileiro, os cupins subterrâneos da espécie Nasutitermes corniger, família Termitidae, são capazes de invadir o meio urbano, atacando móveis e outros objetos construídos com madeira, como batentes de portas e janelas e estruturas de construções (PAES et al., 2010a). Entre os materiais bastante susceptíveis a esses insetos, destaca-se a madeira de sumaúma (Ceiba pentandra), a qual é facilmente encontrada no comércio, sendo muito empregada para os mais diversos fins (PAES et al., 2007).

Para a maioria das regiões brasileiras, a menor quantidade de estudos realizados com térmitas em relação àqueles com fungos xilófagos justifica-se por serem estes últimos os principais agentes deterioradores da madeira utilizada em contato com o solo. No caso do semiárido brasileiro, as características edafoclimáticas não favorecem o desenvolvimento de fungos, mas sim de cupins xilófagos, tanto no meio rural quanto urbano (PAES et al., 2003).

Ainda no Nordeste brasileiro, os curtumes tradicionais exploram o angico-vermelho (Anadenanthera colubrina), com 14\% de taninos na casca (PAES et al., 2010b), como única fonte de taninos, apesar de comprovadamente existirem outras espécies potenciais, tal como a jurema-preta (Mimosa tenuiflora (Willd.) Poir.), que possui um teor de taninos de 17,7\% (PAES et al., 2006a).

Uma vez que os taninos têm composição química variada, suas aplicações também são diferenciadas. Em estudos pioneiros, extratos tânicos obtidos da casca da jurema-preta têm se mostrado de boa qualidade para o curtimento de peles (PAES et al., 2006b; LIMA, 2011). Porém ainda se fazem necessárias pesquisas para avaliar a qualidade dos extratos provenientes dessa espécie para outros usos.

No presente estudo, avaliou-se o rendimento em taninos condensados provenientes de casca de jurema-preta (Mimosa tenuiflora (Willd.) Poir.) e a eficiência de extratos tânicos sulfitados, combinados ou não com ácido bórico, no tratamento da madeira de sumaúma (Ceiba pentandra (L.) Gaerth.) exposta ao térmita xilófago Nasutitermes corniger Motsch. por meio de ensaio de preferência alimentar.

\section{MATERIAL E MÉTODOS}

\section{Obtenção e preparo das cascas}

Utilizaram-se cascas obtidas de nove indivíduos adultos de jurema-preta (Mimosa tenuiflora (Willd.) Poir.) originários do Núcleo de Pesquisas do Semiárido (NUPEÁRIDO), município de Patos, PB. 
Tratando-se de um povoamento natural, as árvores possuíam distintas idades (superior a 30 anos), sendo selecionadas aquelas com diâmetro médio com casca na base de $14 \mathrm{~cm}$.

As cascas foram removidas com auxílio de ferramentas manuais, sendo mantidas em ambiente ventilado para que ocorresse sua secagem natural. Foram fragmentadas inicialmente numa forrageira e, depois, em moinho do tipo Willey, obtendo-se assim um material de menor granulometria. O material obtido foi classificado em peneira, empregando-se a porção de casca que ficou retida na malha de 60 mesh $(0,25 \mathrm{~mm})$.

\section{Preparação do extrato tânico líquido}

A fim de avaliar a influência da adição do sulfito de sódio no rendimento em taninos, realizou-se a extração em água quente destilada e em solução de água destilada mais sulfito de sódio.

Para a obtenção da solução tânica, $12,5 \mathrm{~g}$ de casca absolutamente seca (anidra) foram transferidas para um balão de $500 \mathrm{~mL}$, adicionando-se $250 \mathrm{~mL}$ de água destilada (relação 20:1), sem ou com a inclusão do sulfito de sódio ( $4 \%$ em relação à massa anidra de casca). Ao balão foi conectado um condensador de refluxo, para reduzir as perdas por evaporação, e a mistura foi mantida na temperatura de ebulição da água por duas horas. Após o período de fervura, o material foi passado em peneira de 150 mesh $(0,105 \mathrm{~mm})$, sendo a parte líquida (extrato tânico) armazenada.

\section{Quantificação dos taninos condensados}

Para retirar o excesso de material particulado contido no extrato tânico, realizou-se filtragem do mesmo, inicialmente em tecido de flanela, seguido de uma segunda filtragem em filtro de papel e, finalmente, uma filtragem em cadinho de vidro sinterizado de porosidade 2. Alíquotas de $50 \mathrm{~mL}$ foram destinadas para a determinação do teor de sólidos totais, índice de Stiasny, teor de taninos condensados e teor de não taninos, seguindo metodologia similar à empregada por Teodoro (2008) e Paes et al. (2010b).

Em estufa $\left(103 \pm 2^{\circ} \mathrm{C}\right)$, evaporou-se uma das alíquotas de $50 \mathrm{~mL}$ do extrato tânico até obter sua massa anidra, e calculou-se o teor de sólidos totais, conforme Equação 1, sendo a massa anidra inicial na solução correspondente aos $12,5 \mathrm{~g}$ de casca e a massa anidra final obtida a partir do resíduo dos $50 \mathrm{~mL}$ depois da evaporação na estufa e extrapolado para $250 \mathrm{~mL}$.

$$
\operatorname{TST}(\%)=\left(M_{f} / M_{i}\right) \cdot 100
$$

Em que: TST $(\%)=$ teor de sólidos totais, em porcentagem;

$\mathrm{M}_{\mathrm{f}}=$ massa anidra final da casca nos $250 \mathrm{~mL}$, em gramas;

$\mathrm{M}_{\mathrm{i}}=$ massa anidra inicial da casca nos $250 \mathrm{~mL}$, em gramas.

Em balão volumétrico, à segunda alíquota de $50 \mathrm{~mL}$ do extrato tânico foram adicionados $4 \mathrm{~mL}$ de formaldeído e $1 \mathrm{~mL}$ de ácido clorídrico. O balão foi conectado um condensador de refluxo e a mistura mantida na temperatura de ebulição da água durante 30 minutos, condição em que os taninos condensados formam complexos insolúveis, possibilitando sua separação por filtração simples. O precipitado taninoformaldeído retido no filtro foi posto em estufa $\left(103 \pm 2{ }^{\circ} \mathrm{C}\right)$ e, a partir da sua massa anidra, calculou-se o índice de Stiasny (Equação 2), assim como, posteriormente, o teor de taninos condensados (Equação 3).

$$
I S(\%)=\left(M_{p p} / M_{f f}\right) \cdot 100
$$

Em que: IS $(\%)$ = índice de Stiasny, em porcentagem;

$\mathrm{M}_{\mathrm{pp}}=$ massa anidra do precipitado tanino-formaldeído nos $50 \mathrm{~mL}$, em gramas;

$\mathrm{M}_{\mathrm{ff}}=$ massa anidra final de casca nos $50 \mathrm{~mL}$, em gramas.

$$
\operatorname{TTC}(\%)=(T S T . I S) / 100
$$

Em que: TTC $(\%)=$ teor de taninos condensados, em porcentagem;

TST $(\%)=$ teor de sólidos totais, em porcentagem;

IS $(\%)=$ índice de Stiasny, em porcentagem. 
Calculou-se o teor de não taninos pela diferença entre o teor de sólidos totais e o teor de taninos condensados.

Para cada solução extratora (água destilada ou solução aquosa de sulfito de sódio), foram realizadas cinco extrações (repetições), sendo a quantificação da solução realizada em duplicata para cada repetição.

\section{Obtenção, preparo e caracterização dos corpos de prova}

Utilizou-se madeira de sumaúma (Ceiba pentandra (L.) Gaerth.) obtida de diferentes estabelecimentos madeireiros localizados no município de Patos, Paraíba. De modo aleatório, foram produzidos 84 corpos de prova, livres de defeitos, obtidos da madeira de alburno, com dimensões nominais de $2 \times 2 \times 15 \mathrm{~cm}$ (radial x tangencial x longitudinal). Depois de serem lixados para a retirada de defeitos, eles foram identificados e postos em estufa com circulação de ar $\left(103 \pm 2{ }^{\circ} \mathrm{C}\right)$, para obtenção da massa anidra, tomada como base para a determinação da retenção e perda de massa.

\section{Aplicação dos produtos preservativos}

O extrato tânico que teve maior teor de taninos condensados foi avaliado separadamente e em conjunto (relação 1:1) com o ácido bórico, para a impregnação dos corpos de prova. Adicionalmente, foi avaliada a eficiência dos tratamentos preservativos quanto aos processos de lixiviação (Tabela 1).

Tabela 1. Tipo de solução, submissão à lixiviação e número de repetições da madeira de Ceiba pentandra submetidas a ensaio de preferência alimentar ao cupim xilófago Nasutitermes corniger.

Table 1. Type of solution, submission to leaching, and number of repetitions of Ceiba pentandra wood tested in a food preference against the xilophogous termite Nasutitermes corniger.

\begin{tabular}{lccc}
\hline Tratamento & Solução & Lixiviação & Número de repetições \\
\hline 1 & Nenhuma (Testemunha 1) & Não submetido & 10 \\
2 & Nenhuma (Testemunha 2) & Submetido & 10 \\
3 & Ácido bórico & Não submetido & 11 \\
4 & Ácido bórico & Submetido & 11 \\
5 & Extrato tânico & Não submetido & 11 \\
6 & Extrato tânico & Submetido & 11 \\
7 & Extrato tânico + ácido bórico & Não submetido & 10 \\
8 & Extrato tânico + ácido bórico & Submetido & 10 \\
\hline
\end{tabular}

A concentração do ácido bórico foi estabelecida em $2 \%$, e a do tanino condensado, em função de sua quantidade presente no extrato líquido. Para o tratamento da madeira, foi empregado o método de imersão a frio, em que os corpos de prova, depois de saturados em água e agrupados segundo os tratamentos, foram mantidos submersos em 3 litros da solução (Tabela 1) durante cinco dias. Após a impregnação, os mesmos foram secos ao ar até atingirem teor de umidade de equilíbrio com o ambiente.

\section{Aplicação da lixiviação e avaliação da retenção}

A lixiviação das amostras foi realizada conforme metodologia descrita por Thevenon et al. (1998; 2009; 2010), com as amostras sendo agrupadas por tratamento e submersas em água destilada durante cinco dias em temperatura ambiente, sendo essa água renovada diariamente.

Quando as amostras atingiram o teor de umidade de equilíbrio, foram novamente submetidas à secagem em estufa até que atingissem massa constante (massa anidra). Calculou-se a retenção pela diferença das massas anidras (antes e depois de impregnadas, incluindo a lixiviação quando aplicada), dividida pelos respectivos volumes saturados.

\section{Ensaio de preferência alimentar}

$\mathrm{O}$ ensaio de preferência alimentar foi realizado segundo metodologia similar à empregada por Melo (2009) e Paes et al. (2010c). Em caixa de fibrocimento com capacidade para 250 litros, inseriu-se uma camada de $10 \mathrm{~cm}$ de areia esterilizada em autoclave, a qual foi mantida saturada em água durante todo o experimento, para evitar a morte dos cupins. Os corpos de prova foram dispostos horizontal e aleatoriamente sobre uma 
placa de metal colocada sobre a camada de areia, de maneira que eles não ficassem em contato direto com a areia. Sobre os corpos de prova, foi instalada uma colônia de Nasutitermes corniger, coletada nas proximidades da Universidade Federal de Campina Grande (UFCG), campus de Patos, PB. O ninho possuía aproximadamente $50 \mathrm{~cm}$ de comprimento e $30 \mathrm{~cm}$ de diâmetro, o qual foi totalmente retirado da ramificação do tronco de uma árvore e disposto no interior da caixa de fibrocimento, a fim de incluir todas as castas presentes nesse ninho. Os insetos foram devidamente identificados no Laboratório de Entomologia Florestal da UFCG. O experimento foi montando em uma sala climatizada, com temperatura de $30 \pm 5{ }^{\circ} \mathrm{C}$ e umidade relativa de $70 \pm 10 \%$, sendo os corpos de prova expostos à ação dos cupins durante 40 dias.

\section{Avaliação dos corpos de prova}

Após a exposição aos cupins, os corpos de prova foram limpos com uma escova de cerdas macias e novamente submetidos à secagem em estufa até massa constante, sendo computada a perda de massa porcentual da madeira, conforme recomendação da AFNOR-NFX-41-539, citada por Lopez e Milano (1986). O desgaste das amostras também foi avaliado com base em critério subjetivo, que envolve a atribuição de notas (Tabela 2).

Tabela 2. Avaliação do desgaste dos corpos de prova provocado pelo cupim xilófago Nasutitermes corniger.

Table 2. Evaluation of damage in tests body caused by Nasutitermes corniger xylophagous termite.

\begin{tabular}{lc}
\hline Tipo de desgaste & Nota \\
\hline Sadio & 10 \\
Ataque superficial & 9 \\
Ataque moderado, havendo penetração & 7 \\
Ataque intenso & 4 \\
Falha, com ruptura dos corpos de prova & 0 \\
\hline
\end{tabular}

Fonte: Adaptado de ASTM (1999).

\section{Análise estatística}

Os dados experimentais foram avaliados por meio de análise de variância, sendo a comparação de médias realizada pelo teste LSD (Least Significant Difference ou Diferença Mínima Significativa), de Fischer. Foram conferidas as proposições de normalidade e homocedasticidade (homogeneidade de variância) dos dados, sendo estes transformados para 1/raiz (perda de massa) e (Desgaste ${ }^{2}$ ). As análises foram realizadas a $5 \%$ de probabilidade.

\section{RESULTADOS E DISCUSSÃO}

\section{Quantificação dos extratos tânicos}

O teor de sólidos totais (TST), o índice de Stiasny (IS) e o teor de taninos condensados (TTC) da casca de jurema-preta foram superiores quando a extração foi realizada com a adição do sulfito de sódio à água. O teor de não taninos (TNT), por sua vez, não exibiu diferença estatística significativa (Tabela 3).

Tabela 3. Comparações entre médias do teor de sólidos totais (\%), índice de Stiasny (\%), teor de taninos condensados $(\%)$ e teor de não taninos $(\%)$ dos extratos tânicos da casca de jurema-preta [Mimosa tenuiflora (Willd.) Poir.], obtidos por distintos meios de extração.

Table 3. Comparisons among means of total solid content (\%), Stiasny index (\%), condensate tannin content (\%) and non-tannin content (\%) of tannin extracts from the bark of Mimosa tenuiflora (Willd.) Poir. obtained from different means of extraction.

\begin{tabular}{llccccc}
\hline \multirow{2}{*}{ Tratamento } & $\begin{array}{c}\text { Número de } \\
\text { repetições }\end{array}$ & $\begin{array}{c}\text { Teor de } \\
\text { sólidos totais }(\%)\end{array}$ & $\begin{array}{c}\text { Índice de } \\
\text { Stiasny (\%) }\end{array}$ & $\begin{array}{c}\text { Teor de taninos } \\
\text { condensados (\%) }\end{array}$ & $\begin{array}{c}\text { Teor de não } \\
\text { taninos (\%) }\end{array}$ \\
\hline 1 Água pura & 5 & $11,92 \mathrm{a}^{*}$ & $51,5 \mathrm{a}$ & $6,88 \mathrm{a}$ & $5,04 \mathrm{a}$ \\
& & $(19,9 \%)$ & $(12,6 \%)$ & $(28,3 \%)$ & $(48,5 \%)$ \\
2 & \multirow{2}{*}{$\begin{array}{l}\text { Água + Sulfito } \\
\text { de sódio }\end{array}$} & 5 & $20,72 \mathrm{~b}$ & $77,14 \mathrm{~b}$ & $15,84 \mathrm{~b}$ & $4,88 \mathrm{a}$ \\
\end{tabular}

* Valores seguidos pela mesma letra, numa mesma coluna, não diferem estatisticamente entre si pelo teste LSD de Fischer $(\mathrm{p}>0,05)$. Valores entre parênteses indicam o coeficiente de variação da respectiva média. 
Ao comparar os tratamentos, observa-se que o aumento do TST no tratamento que inclui a adição de sulfito de sódio ocorreu devido à maior extração de substâncias tânicas, conforme indicado pelo IS, que corresponde à quantidade de substâncias presentes no extrato que reagiu com o formaldeído em meio ácido. O IS, portanto, pode ser entendido como a porcentagem de solúveis do extrato correspondente a taninos condensados. Como consequência do aumento do TST e IS, ocorreu aumento do TTC, o qual indica a proporção de taninos presente na solução.

Observa-se que a adição do sulfito de sódio ao meio de extração não promoveu aumento na extração de componentes não tânicos, o que se verifica pela diferença estatística não significativa do TNT, sendo isso um fator positivo. O TNT, portanto, corresponde à porção dos solúveis presentes no extrato que não são taninos, tais como açúcares, gomas e amidos.

Comparando o potencial de espécies florestais de ocorrência no semiárido, Paes et al. (2006a) observaram TTC de 17,7\% para a casca de jurema-preta quando utilizada apenas água como solução de extração. Morais et al. (2009), por sua vez, compararam o TTC extraídos da casca de jurema-preta em água e em solução de 3\% de hidróxido de sódio. Tendo a água e a solução de hidróxido de sódio extraído 16,0 e 16,9\% de taninos condensados, respectivamente, concluíram que a adição de hidróxido de sódio não teve influência significativa no teor de taninos. Esses autores, no entanto, utilizaram partículas de menor granulometria, assim como uma menor relação casca:água à extração, fatores que promoveram uma maior extração das substâncias tânicas quando comparada ao presente estudo.

Portanto, de modo diferente ao hidróxido de sódio, a solução envolvendo sulfito de sódio favoreceu a extração de maior quantidade de taninos condensados, sendo isso reflexo da maior solubilidade dos taninos condensados quando submetidos a este sal. Devido à melhor extração proporcionada pela inclusão do sulfito de sódio, ele foi utilizado para a impregnação das amostras de madeira.

\section{Retenção dos produtos pela madeira}

A retenção, que corresponde à quantidade total da solução fixada, variou conforme os tratamentos preservativos aplicados à madeira de sumaúma (Figura 1).

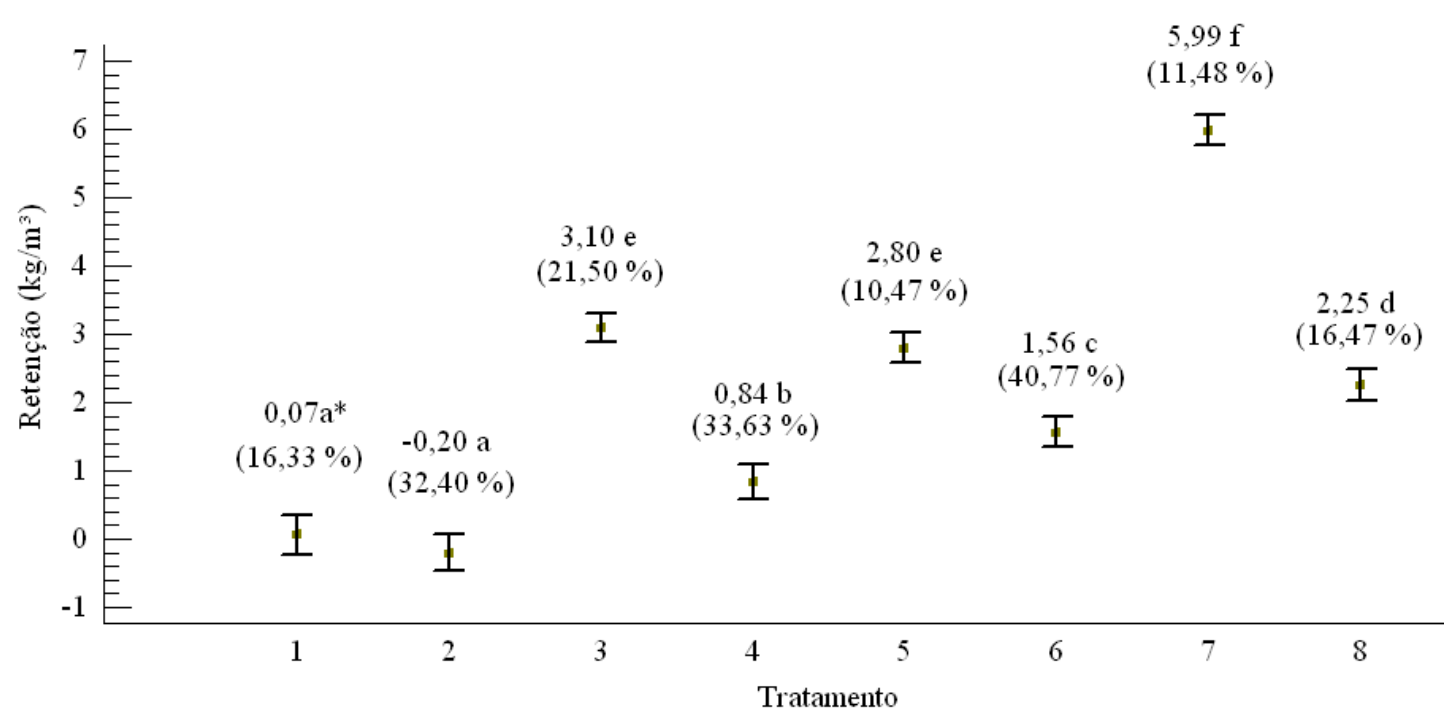

Figura 1. Intervalos de confiança da média (95\%) para a retenção total dos tratamentos preservativos avaliados em madeira de Ceiba pentandra. Valores entre parênteses indicam o coeficiente de variação da respectiva média. "Valores grafados pela mesma letra não diferem estatisticamente entre si pelo teste LSD de Fischer ( $p>0,05)$.

Figure 1. Average confidence intervals (95\%) for the total retention of treatments in Ceiba pentandra wood. Values between parentheses indicate the coefficient variation of its average value. Values graphed by the same letter do not differ significantly by LSD test by Fischer ( $p>0,05)$. 
Quando aplicados isoladamente, tanto o extrato tânico quanto o ácido bórico exibiram comportamentos semelhantes (tratamentos 3 a 6) e superiores aos tratamentos testemunhas (tratamentos 1 e 2). Em todos os casos, observou-se efeito pronunciado da lixiviação, a qual proporcionou redução da retenção. Observou-se uma retenção negativa para a testemunha lixiviada (tratamento 2), fato esse explicável, uma vez que a lixiviação ocasionou a solubilização parcial dos extrativos, em especial açúcares simples e amido, presentes na madeira, reduzindo sua massa quando em comparação com a testemunha que não foi lixiviada (tratamento 1 ).

A melhor retenção ocorreu quando o ácido bórico foi incorporado ao extrato tânico, porém não lixiviado (tratamento 7). No entanto, quando lixiviado, ele mostrou redução drástica dos produtos impregnados (tratamento 8).

Os valores de retenção apresentaram-se aquém do mínimo exigido pela NBR 9480 (ABNT, 2009), a qual estabelece, para preservativos hidrossolúveis, uma retenção mínima de $6,5 \mathrm{~kg}$ de ingrediente ativo por metro cúbico $\left(\mathrm{kg}\right.$ de i.a. $\left./ \mathrm{m}^{3}\right)$ de madeira tratada, para proteger a madeira que ficará em contato direto com o solo. Porém, para peças que não estejam em contato com o solo, mas expostas às intempéries, a mesma norma estabelece uma retenção mínima de $4,0 \mathrm{~kg}$ de i.a. $/ \mathrm{m}^{3}$. Uma maior retenção poderia ser obtida realizando-se a impregnação por meio de algum método com o emprego de vácuo e/ou pressão, tal como em Xavier (2004), Colli et al. (2007), Sen et al. (2009) e Thevenon et al. (2009).

Ao testar uma grande diversidade de produtos com potenciais para serem utilizados como preservativo para madeira, cujas combinações tendem a reduzir a lixiviação do boro, Thevenon et al. (2009) avaliaram o tratamento da madeira de faia (Fagus sylvatica). Entre os tratamentos promissores, descreveram as formulações envolvendo combinações de extrato tânico de Acacia mearnsii com ácido bórico, com a inclusão de hexametilenotetramina (hexamina). A impregnação foi realizada por meio de vácuo-pressão, obtendo-se assim retenções entre 46 e $126 \mathrm{~kg} / \mathrm{m}^{3}$, mantendo-se após os corpos de prova serem submetidos à lixiviação. Depois do teste de apodrecimento acelerado com fungos, observaram que a perda de massa das amostras impregnadas com taninos + ácido bórico + hexamina apresentaram melhores resultados do que os impregnados apenas com taninos + ácido bórico ou taninos + hexamina.

Mesmo comportamento desse estudo foi observado para madeiras de Fagus orientalis e Pinus sylvestris impregnadas com extratos tânicos vegetais, combinados a diferentes concentrações de sais, entre eles o ácido bórico (SEN et al., 2009). Os autores descrevem que a adição de 1\% de ácido bórico aos extratos tânicos obtidos a partir de Quercus macrolepis e Rhus coriaria apresentou-se ideal para gerar efeito positivo sobre a retenção. No entanto, para concentração de sais superiores a $1 \%$, a lixiviação apresentou-se alta. Justificaram esse comportamento descrevendo que os extrativos e os sais deslocaramse isoladamente da solução à madeira, não sofrendo complexação. Além disso, os produtos ficaram acumulados na superfície da madeira, não ocorrendo sua penetração, motivo pelo qual foram facilmente removidos.

\section{Avaliações do ensaio de preferência alimentar}

Ambos os tipos de avaliação (perda de massa e desgaste) apresentaram as mesmas tendências, com diferença estatística significativa e refletindo o comportamento observado na retenção. Dessa forma, os tratamentos com maiores retenções foram menos atacados pelos térmitas (Tabela 4).

Ambos os tipos de avaliações apresentaram alta variabilidade. Esse mesmo comportamento também foi observado por outros autores para estudos semelhantes, exigindo transformação dos dados (COLLI et al., 2007; PAES et al., 2007; PAES et al., 2010a; ALENCAR et al., 2011; PAES et al., 2011).

Não se observaram diferenças estatísticas significativas entre o uso do ácido bórico e do extrato tânico quando aplicados isoladamente. No entanto, mostraram tendência de repelência aos cupins quando comparados aos tratamentos-testemunha. O tratamento que envolveu a introdução de ácido bórico ao extrato tânico sulfitado, quando não lixiviado, gerou a maior repelência, prejudicada quando da lixiviação (tratamento 8), sendo o único que se apresentou influenciado pela lixiviação (considerando a avaliação realizada pela perda de massa). Nos demais casos não se observou diferença estatística significativa, devido à lixiviação para corpos de prova impregnados com o mesmo produto (ácido bórico ou extrato tânico).

Comparando-se os tratamentos que não foram submetidos à lixiviação, ocorreu destaque ao uso do extrato tânico combinado ao ácido bórico, com diferença estatística significativa aos demais tratamentos quando avaliado através da perda de massa. Repelência superior à testemunha (não lixiviada) 
também foi observada pelo uso do ácido bórico e do extrato tânico quando os mesmos foram utilizados separadamente. No entanto, deve-se levar em consideração a maior retenção observada ao tratamento incluindo extrato tânico e ácido bórico simultaneamente, uma vez que a maior repelência pode estar diretamente relacionada a esse fator.

Tabela 4. Comparação de médias para as avaliações através da perda de massa e desgaste da madeira de Ceiba pentandra submetida ao ensaio de preferência alimentar. Análises de variância e comparações de médias realizadas com dados transformados: 1/raiz (perda de massa) e $\left(\right.$ Desgaste $\left.^{2}\right)$. Médias e coeficientes de variação são apresentados nos valores originais.

Table 4. Comparison of averages for evaluation of Ceiba pentandra wood submitted to test food. Analysis of variance and mean comparisons carried out with transformed data: 1/root (mass loss) and $\left(\mathrm{Wear}^{2}\right)$. Averages and variation coefficients are presented in the original values.

\begin{tabular}{|c|c|c|c|c|}
\hline \multirow{2}{*}{\multicolumn{3}{|c|}{ Tratamento }} & \multicolumn{2}{|c|}{ Avaliação } \\
\hline & & & \multirow{2}{*}{$\begin{array}{c}\text { Perda de massa }(\%) \\
5,46 \mathrm{a}^{*} \\
(139,26 \%)\end{array}$} & \multirow{2}{*}{$\begin{array}{c}\text { Desgaste } \\
6,10 \mathrm{ab} \\
(65,87 \%)\end{array}$} \\
\hline 1 & Testemunha 1 & Não lixiviado & & \\
\hline 2 & Testemunha 2 & Lixiviado & $\begin{array}{c}4,86 \mathrm{ab} \\
(153,53 \%)\end{array}$ & $\begin{array}{c}5,7 \mathrm{a} \\
(62,68 \%)\end{array}$ \\
\hline 3 & Ácido bórico & Não lixiviado & $\begin{array}{l}2,71 \mathrm{abc} \\
(80,55 \%)\end{array}$ & $\begin{array}{c}7,40 \mathrm{abc} \\
(42,18 \%)\end{array}$ \\
\hline 4 & Ácido bórico & Lixiviado & $\begin{array}{l}2,55 \mathrm{abc} \\
(38,85 \%)\end{array}$ & $\begin{array}{c}8,10 \mathrm{c} \\
(17,68 \%)\end{array}$ \\
\hline 5 & Extrato tânico & Não lixiviado & $\begin{array}{c}2,01 \mathrm{c} \\
(154,75 \%)\end{array}$ & $\begin{array}{c}8,50 \mathrm{c} \\
(40,16 \%)\end{array}$ \\
\hline 6 & Extrato tânico & Lixiviado & $\begin{array}{c}2,46 \mathrm{bc} \\
(122,76 \%)\end{array}$ & $\begin{array}{c}8,20 \mathrm{c} \\
(39,40 \%)\end{array}$ \\
\hline 7 & Extrato tânico e ácido bórico & Não lixiviado & $\begin{array}{c}0,02 \mathrm{~d} \\
(162,60 \%)\end{array}$ & $\begin{array}{c}9,10 \mathrm{c} \\
(10,73 \%)\end{array}$ \\
\hline 8 & Extrato tânico e ácido bórico & Lixiviado & $\begin{array}{c}2,19 \mathrm{c} \\
(169,47 \%)\end{array}$ & $\begin{array}{c}8,00 \mathrm{bc} \\
(53,71 \%)\end{array}$ \\
\hline
\end{tabular}

*Valores seguidos pela mesma letra, numa mesma coluna, não diferem estatisticamente entre si pelo teste LSD de Fischer $(\mathrm{p}>0,05)$. Valores entre parênteses indicam o coeficiente de variação da respectiva média.

Considerando-se os tratamentos que foram submetidos à lixiviação, a impregnação por qualquer dos produtos (incluindo a combinação de ambos) gerou repelências semelhantes, os quais diferiram estatisticamente da testemunha. Essa tendência mostrou-se válida para ambos os métodos de avaliação.

Produtos preservativos com diferentes formulações de boro e taninos de acácia-negra (Acacia mearnsii), além de testemunha (borato de cobre cromatado - $\mathrm{CCB}$ ), foram aplicados a colmos de Phyllostachys aurea por Xavier (2004). As retenções totais variaram de 14,5 a $22,7 \mathrm{~kg} / \mathrm{m}^{3}$, sendo que foram tratados pelo método de pressão. Considerando-se os testes realizados fora do contato com o solo, tratamentos envolvendo maiores retenções de boro apresentaram efeito inseticida mais pronunciado a cupins que aqueles com maiores retenções de tanino. Essa mesma conclusão foi descrita por Colli et al. (2007) em estudo semelhante.

A repelência aos cupins proporcionada pelo boro deve-se a seu reconhecido efeito inseticida (MENDES; ALVES, 1988). Com relação ao extrato tânico, os resultados observados corroboram estudos de Sen et al. (2009), que descrevem que alguns extratos usados na indústria do couro proporcionam positivos efeitos antimicrobianos, antifúngicos e inseticidas.

Quando da combinação de ambos, no entanto, os produtos se complementaram e formaram uma dupla camada superficial protetora, sendo lixiviada, o que aumentou sua suscetibilidade aos insetos.

\section{CONCLUSÕES}

- O rendimento em taninos condensados obtido a partir da casca de jurema-preta foi de aproximadamente $7 \%$ quando a extração foi realizada apenas com água destilada. No entanto, com a inclusão de sulfito de sódio na solução extratora, o rendimento apresentou-se em 15,8\%. 
- O extrato tânico sulfitado mostrou-se eficiente para ser utilizado como repelente ao cupim em madeira de sumaúma, principalmente quando combinado ao ácido bórico. No entanto, estudos adicionais fazem-se necessários para uma melhor avaliação e melhoria do seu desempenho.

\section{REFERÊNCIAS}

ALENCAR, F. H. H.; PAES, J. B.; BAKKE, O. A.; SILVA, G. S. Resistência natural da madeira de sabiá (Mimosa caesalpiniifolia Benth.) a cupins subterrâneos. Caatinga, Mossoró, v. 24, n. 1, p. 57 - 64, 2011.

AMERICAN SOCIETY FOR TESTING AND MATERIALS (ASTM). D 3345: Standard method for laboratory evaluation of wood and other cellulosic materials for resistance to termite. Philadelphia, 1999.

ASSOCIAÇÃO BRASILEIRA DE NORMAS TÉCNICAS (ABNT). NBR 9480: peças roliças preservadas de eucalipto para construções rurais - Requisitos. Rio de Janeiro, 2009.

BRAND, M. A.; ANZALDO, J.; MORESCHI, J. C. Novos produtos para o tratamento preservante da madeira: perspectivas da pesquisa e utilização. Floresta, Curitiba, v. 36, n. 1, p. 129 - 138, 2006.

COLLI, A.; NASCIMENTO, A. M.; XAVIER, L. M.; RUBIM, I. B. Propriedades físico-mecânicas e preservação, com boro e tanino, de Bambusa tuldoides (Munro). Floresta e Ambiente, Seropédica, v. 14, n. 1, p. $56-64,2007$.

JORGE, F. C.; BRITO, P.; PEPINO, L.; PORTUGAL, A.; GIL, H.; COSTA, R. P. Aplicações para as cascas de árvores e para os extractos taninosos: uma revisão. Silva Lusitana, Oeiras, v. 9, n. 2, p. 225 236, 2001.

LAKS, P. E.; MCKAIG, P. A. Flavonoid biocides: wood preservatives based on condensed tannins. Holzforschung, Neugersdorf, v. 42, n. 5, p. 299 - 306, 1988.

LIMA, C. R. Potencialidade dos extratos tânicos das espécies angico-vermelho, jurema-preta e jurema-vermelha no curtimento de peles caprinas. $61 \mathrm{f}$. Tese (Doutorado em Recursos Naturais) Universidade Federal de Campina Grande, Centro de Tecnologia e Recursos Naturais, 2011.

LOPEZ, G. A. C.; MILANO, S. Avaliação da durabilidade natural da madeira e de produtos usados na sua proteção. In: LEPAGE, E. S. (Coord.). Manual de preservação de madeiras. São Paulo: IPT, 1986. p. $473-521$.

MELO, R. R.; SANTINI, E. J.; HASELEIN, C. R.; GARLET, A.; PAES, J. B.; STANGERLIN, D. M. Resistência de painéis aglomerados produzidos com diferentes proporções de madeira e casca de arroz a fungos e cupins xilófagos. Ciência Florestal, Santa Maria, v. 20, n. 3, p. 501 - 511, 2010.

MELO, R. R. Propriedades físico-mecânicas e resistência a biodeterioradores de chapas aglomeradas constituídas por diferentes proporções de madeira e casca de arroz. $77 \mathrm{f}$. Dissertação (Mestrado em Engenharia Florestal) - Universidade Federal de Santa Maria, Santa Maria, 2009.

MENDES, A. S.; ALVES, M. V. S. A degradação da madeira e sua preservação. Brasília: IBDF/LPF, 1988. $57 \mathrm{p}$.

MORAIS, R. M.; SANTANA, G. M.; PAES, J. B.; SILVA, C. P. L.; LUCENA, D. S.; LIMA, C. R. Taninos condensados extraídos de Mimosa tenuiflora (Willd.) Poir. (Mimosoideae) em água e hidróxido de sódio. In: CONGRESSO NORDESTINO DE ENGENHARIA FLORESTAL, 2. 2009. Campina Grande. Anais... Campina Grande: UFCG, 2009. CD-ROM.

OBANDA, N. D.; SHUPE, T. F.; BARNES, H. M. Reducing leaching of boron based wood preservatives - A review of research. Bioresource Technology, New York, v. 99, n. 15, p. 7312 - 7322, 2008.

PAES, J. B.; MORAIS, V. M.; FARIAS SOBRINHO, D. W.; BAKKE, O. A. Resistência natural de nove madeiras do semiárido brasileiro a cupins subterrâneos, em ensaio de laboratório. Cerne, Lavras, v. 9, n. 1, p. $36-47,2003$.

PAES, J. B.; DINIZ, C. E. F.; MARINHO, I. V.; LIMA, C. R. Avaliação do potencial tanífero de seis 
espécies florestais de ocorrência no semiárido brasileiro. Cerne, Lavras, v. 12, n. 3, p. 232 - 238, 2006 a.

PAES, J. B.; MARINHO, I. V.; LIMA, R. A.; LIMA, C. R.; AZEVEDO, T. K. B. Viabilidade técnica dos taninos de quatro espécies florestais de ocorrência no semiárido brasileiro no curtimento de peles. Ciência Florestal, Santa Maria, v. 16, n. 4, p. 453 - 462, 2006b.

PAES, J. B.; MELO, R. R.; LIMA, C. R.; OLIVEIRA, E. Resistência natural de sete madeiras ao cupim subterrâneo (Nasutitermes corniger Motsch.) em ensaio de preferência alimentar. Revista Brasileira de Ciências Agrárias, Recife, v. 2, n. 1, p. 57 - 62, 2007.

PAES, J. B.; SOUZA, A. D.; LIMA, C. R.; MEDEIROS NETO, P. N. Eficiência dos óleos de nim e mamona contra cupins xilófagos em ensaio de alimentação forçada. Cerne, Lavras, v. 16, n. 1, p. 105113, 2010a.

PAES, J. B.; SANTANA, G. M.; AZEVEDO, T. K. B.; MORAIS, R. M.; CALIXTO JÚNIOR, J. T. Substâncias tânicas presentes em várias partes da árvore angico-vermelho (Anadenanthera colubrina (Vell.) Brenan. var. cebil (Gris.) Alts.). Scientia Forestalis, Piracicaba, v. 38, n. 87, p. 441 - 447, 2010 b.

PAES, J. B.; FONSÊCA, C. M. B.; LIMA, C. R.; SOUZA, A. D. Eficiência do óleo de candeia na melhoria da resistência da madeira de sumaúma a cupins. Cerne, Lavras, v. 16, n. 2, p. 217 - 225, 2010c.

PAES, J. B.; SOUZA, A. D.; LIMA, C. R.; MEDEIROS NETO, P. N. Eficiência dos óleos de nim (Azadirachta indica) e de mamona (Ricinus communis) na proteção da madeira de sumaúma (Ceiba pentandra) contra cupins xilófagos em ensaio de preferência alimentar. Revista Árvore, Viçosa, v. 35, n. 3, p. $751-758,2011$.

PIZZI, A.; BAECKER, A. A new boron fixation mechanism for environment friendly wood preservatives. Holzforschung, Berlin, v. 50, n. 6, p. 507 - 510, 1996.

SEN, S.; TASCIOGLU, C.; TIRAK, K. Fixation, leachability, and decay resistance of wood treated with some commercial extracts and wood preservative salts. International Biodeterioration \& Biodegradation, London, v. 63, n. 2, p. 135 - 141, 2009.

TEODORO, A. S. Utilização de adesivos à base de taninos na produção de painéis de madeira aglomerada e OSB. 91 f. Dissertação (Mestrado em Ciências Ambientais e Florestais) - Universidade Federal Rural do Rio de Janeiro, Instituto de Florestas, 2008.

THEVENON, M. F.; PIZZI, A.; HALUK, J. P. One-step tannin fixation of non-toxic protein borates wood preservatives. Holz Roh-Werkst., Berlin, v. 56, n. 1, p. 90. 1998.

THEVENON, M. F.; TONDI, G.; PIZZI, A. High performance tannin resin-boron wood preservatives for outdoor end-uses. European Journal of Wood Products, Heidelberg, v. 67, n. 1, p. 89 - 93, 2009.

Environmentally friendly wood preservative system based on polymerized tannin resin-boric acid for outdoor applications. Maderas: Ciencia y Tecnologia, Concepción, v. 12, n. 3, p. 253 - 257, 2010.

XAVIER, L. M. Caracterização química, física e mecânica do Phyllostachys aurea e sua resistência ao ataque de térmitas, preservado com ácido bórico e tanino condensável. $44 \mathrm{f}$. Dissertação (Mestrado em Ciências Ambientais e Florestais) - Universidade Federal Rural do Rio de Janeiro, Seropédica, 2004. 